\title{
Bioprocess Modelling of Biohydrogen Production by Rhodopseudomonas palustris: Model Development and Effects of Operating Conditions on Hydrogen Yield and Glycerol Conversion Efficiency
}

\author{
D. Zhang, N. Xiao, K. T. Mahbubani, E. A. del Rio-Chanona, N. K. H. Slater, V. S. Vassiliadis ${ }^{1}$ \\ Department of Chemical Engineering and Biotechnology, University of Cambridge, Pembroke Street, Cambridge \\ CB2 3RA, UK.
}

\begin{abstract}
This research explores the photofermentation of glycerol to hydrogen by Rhodopseudomonas palustris, with the objective to maximise hydrogen production. Two piecewise models are designed to simulate the entire growth phase of $R$. palustris; a challenge that few dynamic models can accomplish. The parameters in both models were fitted by the present batch experiments through the solution of the underlying optimal control problems by means of stable and accurate discretisation techniques. It was found that an initial glutamate to glycerol ratio of 0.25 was optimal, and was independent of the initial biomass concentration. The glycerol conversion efficiency was found to depend on initial biomass concentration and its computational peak is $64.4 \%$. By optimising a 30-day industrially relevant batch process, the hydrogen productivity was improved to be 37.7 $\mathrm{mL} \cdot \mathrm{g}$ biomass ${ }^{-1} \cdot \mathrm{hr}^{-1}$ and the glycerol conversion efficiency was maintained at $58 \%$. The models can then be applied as the connection to transfer biohydrogen production from laboratory scale into industrial scale.

Keywords: purple non-sulphur bacteria; photofermentation; dynamic simulation; process optimisation; discretisation;
\end{abstract}

\footnotetext{
${ }^{1}$ corresponding author. email: vsv20@cam.ac.uk, tel: 44 (0)1223 330142.
} 


\section{Introduction}

Hydrogen is considered to be one of the fuels for the future with the highest potential, as it has a high combustion energy and the combustion product is only water which is totally environmental friendly $[1,2]$. Because of its advantages, hydrogen is considered to be a promising clean transport fuel for the future $[3,4]$. Currently, photosynthetic bacteria such as purple non-sulphur (PNS) bacteria are the best prospective microorganisms generating biological hydrogen compared to other typical used microorganisms such as green algae and cyanobacteria [5]. The unique advantages of PNS bacteria are their high conversion efficiency of organic carbon source to hydrogen, lack of oxygen generation during photosynthesis and ability to use broad spectra of light wavelengths [5]. These factors contribute to the feasibility of PNS bacteria being used for industrial biohydrogen production.

\subsection{Biohydrogen production}

Rhodopseudomonas palustris, a purple non-sulphur bacterium, is known to produce good yields of hydrogen during anaerobic photoheterotrophic growth, which is the reason it was chosen for this study. It is capable of converting molecular nitrogen $\left(\mathrm{N}_{2}\right)$ into ammonia $\left(\mathrm{NH}_{3}\right)$ for protein synthesis during cell growth. Additionally $\mathrm{H}^{+}$ions from the electron donors such as organic carbon sources are converted to hydrogen gas $\left(\mathrm{H}_{2}\right)$ by the enzyme nitrogenase. Reduction energy obtained from light as well as carbon oxidation is required for both cell growth and $\mathrm{H}_{2}$ production. If $\mathrm{N}_{2}$ is removed, all substrate and energy are theoretically directed towards $\mathrm{H}_{2}$ production without cell growth, i.e. the nitrogenase performs as a hydrogenase converting $\mathrm{H}^{+}$ions to $\mathrm{H}_{2}[6,7]$.Extensive research to improve the performance of PNS bacteria hydrogen production, for instance, comparing different organic carbon sources such as glycerol, lactate and acetate have been conducted to explore the carbon source conversion efficiency for $R$. palustris growth and hydrogen production [5, 8].

Meanwhile, the scale-up of biohydrogen production process from different species has been widely conducted recently. For green algal hydrogen production, a 21-day fed-batch process (13.6 $\mathrm{mL} \mathrm{H}_{2} \cdot \mathrm{g}$ biomass $\left.^{-1} \cdot \mathrm{hr}^{-1}\right)$ and a 23 -day fed-batch process $\left(1.8 \mathrm{~mL} \mathrm{H}_{2} \cdot \mathrm{g}\right.$ biomass $\left.{ }^{-1} \cdot \mathrm{hr}^{-1}\right)$ have been

reported by Vijayaraghavan et al. [9], Kim et al. [10], respectively. For cyanobacterial hydrogen 
production, a 31-day continuous process has been designed by Dechatiwongse et al. [11] (11.1 mL $\mathrm{H}_{2} \cdot \mathrm{g}$ biomass $\left.^{-1} \cdot \mathrm{hr}^{-1}\right)$. For PNS hydrogen production, a 30-day fed-batch process $\left(37.9 \mathrm{~mL} \mathrm{H}_{2} \cdot \mathrm{g}\right.$ biomass $\left.{ }^{-1} \cdot \mathrm{hr}^{-1}\right)$ and a 24 -day fed-batch process $\left(16.7 \mathrm{~mL} \mathrm{H}_{2} \cdot \mathrm{g}\right.$ biomass $\left.^{-1} \cdot \mathrm{hr}^{-1}\right)$ have been developed by Boran et al. [12], Lee et al. [13], respectively. By comparing the average hydrogen productivity of each process, it is seen that PNS shows the best prospective due to its highest productivity.

\subsection{Methods for biohydrogen process simulation and optimisation}

However, unresolved problems such as determining the effects of light intensity on the growth rate of $R$. palustris, hydrogen production, optimal ratio of nitrogen source to organic carbon source $(\mathrm{N} / \mathrm{C}$ ratio) and photobioreactor configuration still restrict the application of PNS bacteria in a commercial photofermentation process [5]. One feasible way to solve these problems is to design a process simulation and optimisation model, as it is quite time consuming to solve such problems purely through experiments. Two methods are generally considered: the response surface methodology (RSM) and dynamic simulation.

RSM is a statistical technique which explores the relationship between several decision variables and one or more response variables [14]. The main idea is to use a sequence of designed experiments to obtain an optimal response. A second-degree polynomial model is usually used to fit experimental results [15]. The detailed introduction of RSM and statistical experimental design methods can be found in Box and Wilson [16], Mead and Pike [17]. Because the decision variables and response variables are assumed to be related by a polynomial equation, no kinetic information of bioreactions is needed in this method and the biosystem is effectively treated as a black box. Therefore, this method is very convenient for implementation and has been extensively utilised for the optimisation of operating conditions in different fermentation processes [18, 19].

However, several problems of RSM restrict its applicability in general bioprocess optimisation. Relationships between response variables (such as carbon source conversion efficiency) and decision variables (light intensity, initial nutrient concentration etc. etc.) are very complicated and cannot be captured by simple polynomial models. Thus a quadratic model may lead to large errors when determining the optimal value of decision variables, and the accuracy of RSM is strongly dependent 
on the strategy of experimental design. Furthermore, this method is not able to simulate the dynamic course of a fermentation process as time is not involved in this method. As a result, RSM can only provide rough optimal values [16] and is not selected for the present study.

Dynamic models, on the other hand, are constructed based on the biochemical mechanisms of microorganisms , and have been widely applied to simulate different fermentation processes. Compared to RSM which treats the biosystem as a black box, the dynamic simulation approach is more accurate and the parameters in the models are characterised by physical meanings [20]. To represent accurately each growth phase, different dynamic models have been proposed [21, 22, 23, 24] to take into account the effect of nutrient concentration, light intensity, temperature and $\mathrm{pH}$ so as to characterise cell growth and bioproduct production. Despite its advantages and generality, two challenges strongly limit the use of dynamic simulation using mechanistic models.

First, because of the complex metabolic mechanisms of microorganisms, a fermentation process generally includes different microorganism growth phases, from the lag phase to the decay phase with the change of operating conditions. It is very difficult to construct a dynamic model capable of simulating the whole bioprocess by capturing the behaviour of the system through all these phases. For example, although different dynamic models have been proposed to simulate PNS bacteria and green algal hydrogen processes recently $[25,26,27,28]$, most of them are only able to simulate the exponential growth and stationary phases. They fail to simulate the decay phase, where cells commence to die, and the secondary growth phase, where nutrients have been consumed and hydrogen is mainly produced. Therefore, they are not suitable to design and optimise the operating conditions in an adequate fashion. This is a general problem in biochemical process simulation by mechanistic models, in that the underlying process mechanisms are not fully understood and hence difficult to correlate with kinetic expressions.

Parameter estimation in dynamic models is the other challenging task. Although the parameter estimation process is also based on the least-squares principle, discretisation of differential equations has to be implemented before parameter optimisation. Due to the high nonlinearity of dynamic models in bioprocesses, simple discretisation strategies such as explicit Euler methods are inadequate, being unstable when faced with stiff systems [29]. Stiff systems represent coupled 
dynamic systems having components varying with very different time scales [30]. In recent models $[22,25,24,27]$ biomass concentration during processing does not change fast, but the limiting nutrient concentration either decreases rapidly in a batch process or increases suddenly in a fed-batch process after replenishment. However, values of parameters in these models were either calculated by an explicit Euler method or obtained from other publications in which experimental operating conditions and microorganism species were not exactly the same $[22,25,24,27]$. The accuracy of these models therefore cannot be guaranteed.

To solve the above challenges, the current research aims to construct a model which is capable of simulating the most of the growth phases of in the hydrogen production process and guarantee the high accuracy of parameter estimation. Based on the dynamic model developed, the current research also explores the effects of operating conditions such as starting nutrient concentrations, carbon source conversion efficiency and fermentation operating time on hydrogen production. Furthermore, a short-term photofermentation process lasting for 30 days (720 hours) will also be constructed by the present simulation work to analyse the optimal operating condition for $R$. palustris biohydrogen production, and to compare with the the previous 30-day and 24-day PNS hydrogen production processes $[12,13]$.

\section{Experiment methods}

\subsection{Fermentation of R. palustris}

The cell line $R$. palustris, with strain designation ATH 2.1.37 (NCIB 11774) was purchased from American Tissue Culture Collection as a freeze-dried axenic sample. For the experiment, $R$. palustris was initially cultivated in nitrogen fixing photosynthetic medium [31] with glycerol as the carbon source and sodium glutamate as the nitrogen source. $R$. palustris is assumed to have a formula of $\mathrm{CH}_{1.8} \mathrm{~N}_{0.8} \mathrm{O}_{0.38}$ [32]; the concentrations of glycerol and sodium glutamate supplemented into the growth medium were selected as $10 \mathrm{mM}$ and $5.4 \mathrm{mM}$ respectively, ensuring the carbon to nitrogen ration is 1:0.18 for the cell growth stage. As the carbon source becomes limiting, the bacteria reached the stationary phase. The cells were harvested, centrifuged to remove any remaining nitrogen source, and diluted with fresh medium to a fixed cell concentration within the 
exponential growth phase $\left(\mathrm{OD}_{660}=0.5\right)$. The cell mixture was re-cultivated in $10 \mathrm{mM}$ glycerol for the commencement of the non-growing hydrogen production stage. Argon was sparged into the medium headspace to create anaerobic and nitrogen-free conditions. An incandescent light source was selected, and the light intensity was kept at $174 \mathrm{~W} / \mathrm{m}^{2}$. The environmental temperature was kept at $25 \pm 2{ }^{\circ} \mathrm{C}$.

\subsection{Analysis techniques}

The concentration of glycerol in the medium was determined by an adapted method to determine glycerol concentration in biodiesel [33]. A ninhydrin colorimetric method described by Wang [34] was used to measure glutamate concentration. The gas volume was measured by water replacement, while the gas composition was analysed by gas chromatography (GC). The biomass concentration was determined by optical density using an absorbance spectrophotometer at $660 \mathrm{~nm}$.

\section{Methodology of model construction}

\subsection{Dynamic model construction}

From the experiment results, three growth phases of $R$. palustris are found. An initial lag phase, which is not considered a growth phase for model construction. This is followed by the primary growth phase where bacteria grows very fast because of the presence of both nitrogen and carbon sources at high unlimited concentrations. Once the glutamate is depleted, bacteria continue to grow for a short period using the remaining glycerol present. This secondary growth phase occurs as cells can consume the nitrogen quota (intracellular nitrogen source) reserved from the primary growth phase. The secondary growth phase is slower than the primary growth phase and has a decreasing growth rate with time as the nitrogen quota is consumed.

The secondary growth phase stops when nitrogen quota falls below the minimum threshold. This commences the stationary phase, where the biomass concentration is maintained by the presence and consumption of glycerol. For the current experimental work, the secondary growth phase is 
maintained for less than 90 hours, significantly shorter than the primary growth and the stationary phases (more than 200 hours each).

Hydrogen production is known to take place in all of three growth phases, suggesting that glutamate does not inhibit hydrogen production (the secondary growth phase is glutamate-free). All the three growth phases will be included in the model development. To construct an accurate dynamic model able to simulate the three growth periods of $R$. palustris and determine the influence of limiting nutrient on bacteria growth; two modified models both originating from the Droop model and the Contois model are considered for the current simulation [20].

Parameters for the models can not be accurately calculated if the experimental results including the three growth phases are used simultaneously, as different growth phases are dominated by distinct and individual growth mechanisms. To solve this problem, piecewise models are developed to decompose the modified models into different sub-models which correspond to different growth phases. Parameters in each sub-model will be accurately fitted to experimental results. Switch functions, similar to the Heaviside step function but differentiable, are used to combine the submodels and mediate the start and termination steps in each phase $[35,36]$.

\subsubsection{The piecewise Droop model}

The Droop model is very common for simulation of microorganism fermentation[20]. In the Droop model, the growth rate of microorganism is not only affected by the concentration of limiting nutrients, but also decided by the intracellular concentration of the limiting nutrient, which is usually termed as nutrient quota (mg nutrient/g biomass) [20]. Equations (1a) to (1e) show the original Droop model.

$$
\begin{gathered}
\frac{\mathrm{dX}}{\mathrm{dt}}=\mu_{\max } \cdot f(\mathrm{Q}) \cdot \mathrm{X} \\
\frac{\mathrm{dQ}}{\mathrm{dt}}=Y_{\mathrm{S}} \cdot \frac{\mathrm{S}}{\mathrm{S}+K_{\mathrm{S}}}-\mu_{\max } \cdot f(\mathrm{Q}) \cdot \mathrm{Q}
\end{gathered}
$$




$$
\begin{gathered}
\frac{\mathrm{dS}}{\mathrm{dt}}=-Y_{\mathrm{S}} \cdot \frac{\mathrm{S}}{\mathrm{S}+K_{\mathrm{S}}} \cdot \mathrm{X} \\
\frac{\mathrm{dP}}{\mathrm{dt}}=Y_{\mathrm{P}} \cdot \frac{\mathrm{S}}{\mathrm{S}+K_{\mathrm{S}}} \cdot \mathrm{X} \\
f(\mathrm{Q})=1-\frac{k_{\mathrm{Q}}}{\mathrm{Q}}
\end{gathered}
$$

The Droop model assumes that the production rate of fermentation product is proportional to microorganism growth and can be calculated by Equation (1d). The current experimental study determined that non-growing $R$. palustris are still able to continuously generate hydrogen, thus the original Droop model has to be modified. Equation (1d) is thereby modified to Equation (2) originating from the Luedeking-Piret Model [25]. The consumption rate of glycerol is also modified from Equation (1c) to Equation (3). In Equation (3), the first term on the right-hand-side represents the consumption rate of substrate due to cell growth, and the second term represents the consumption rate of substrate due to cell maintenance. Similarly, the first term on the right-handside of Equation (2) denotes the growth-associated production rate, while the second term denotes the growth-independent production rate.

$$
\begin{aligned}
& \frac{\mathrm{dP}}{\mathrm{dt}}=Y_{\mathrm{P} 1} \cdot \frac{\mathrm{dX}}{\mathrm{dt}}+Y_{\mathrm{P} 2} \cdot \mathrm{X} \\
& \frac{\mathrm{dS}}{\mathrm{dt}}=-Y_{\mathrm{S} 1} \cdot \frac{\mathrm{dX}}{\mathrm{dt}}-Y_{\mathrm{S} 2} \cdot \mathrm{X}
\end{aligned}
$$

In the original Droop model, the influence of nutrient quota on microorganism growth is determined by $f(\mathrm{Q})$, usually expressed as Equation (1e) (Vatcheva et al. 20). However, Equation (1e) lacks a theoretical explanation and previous research [37] has declared that it is not applicable for green algae hydrogen production simulation, as the expression of $f(\mathrm{Q})$ is difficult to determine. Additionally, as the experiment setup cannot measure nitrogen quota, $f(\mathrm{Q})$ is replaced by a 
normalised nitrogen quota defined as Equation (4) for this study.

$$
\mathrm{q}=\frac{\mathrm{Q}}{\mathrm{Q}_{0}}
$$

where $Q_{0}$ represents the absolute nitrogen quota of $R$. palustris when the culture media has sufficient glutamate and glycerol to support the primary growth phase.

Thus, the original Droop models are modified to a piecewise Droop model, which consists of three sub-models which corresponding to the three growth phases mentioned in Section 3.1. During the primary growth phase where both glutamate and glycerol are present, it assumes the loss of nitrogen quota can be rapidly replenished by glutamate; Equation (1a) is thereby replaced by Equation (6) from the Monod model. During the secondary growth phase where only glycerol is present, it is acceptable to use an average growth rate, $\mu_{0}$, to replace the influence of the nitrogen quota on bacteria growth, especially as bacteria grows slowly and this phase only lasts for a relatively short time.

After the depletion of glutamate, the total nitrogen quota $(\mathrm{q} \cdot \mathrm{X})$ is a constant because there is no replenishment. It is easy to calculate the consumption rate of nitrogen in each cell by Equation (5). The piecewise Droop model is shown from Equations (7a) to (7e).

$$
\begin{gathered}
\frac{\mathrm{dq}}{\mathrm{dt}}=-\frac{\mathrm{q}}{\mathrm{X}} \cdot \frac{\mathrm{dX}}{\mathrm{dt}} \\
\frac{\mathrm{dX}}{\mathrm{dt}}=\mu_{\max } \cdot \frac{\mathrm{C}}{\mathrm{C}+K_{\mathrm{C}}} \cdot \frac{\mathrm{N}}{\mathrm{N}+K_{\mathrm{N}}} \cdot \mathrm{X} \\
\frac{\mathrm{dX}}{\mathrm{dt}}= \begin{cases}\mu_{\max } \cdot \frac{\mathrm{C}}{\mathrm{C}+K_{\mathrm{C}}} \cdot \frac{\mathrm{N}}{\mathrm{N}+K_{\mathrm{N}}} \cdot \mathrm{X} & \mathrm{N}>0 \\
\mu_{0} \cdot \frac{\mathrm{C}}{\mathrm{C}+K_{\mathrm{C}}} \cdot \mathrm{X} & \mathrm{q}>\mathrm{q}_{\min } \\
0 & \mathrm{q} \leq \mathrm{q}_{\min }\end{cases}
\end{gathered}
$$




$$
\begin{aligned}
& \frac{\mathrm{dq}}{\mathrm{dt}}= \begin{cases}Y_{\mathrm{q}} \cdot \mu_{\max } \cdot \frac{\mathrm{N}}{\mathrm{N}+K_{\mathrm{N}}}-\mu_{\max } \cdot \frac{\mathrm{C}}{\mathrm{C}+K_{\mathrm{C}}} \cdot \frac{\mathrm{N}}{\mathrm{N}+K_{\mathrm{N}}} \cdot \mathrm{q} & \mathrm{N}>0 \\
-\mu_{0} \cdot \frac{\mathrm{C}}{\mathrm{C}+K_{\mathrm{C}}} \cdot \mathrm{q} & \mathrm{q}>\mathrm{q}_{\min } \\
0 & \mathrm{q} \leq \mathrm{q}_{\min }\end{cases} \\
& \frac{\mathrm{dN}}{\mathrm{dt}}=-Y_{\mathrm{N}} \cdot \mu_{\max } \cdot \frac{\mathrm{N}}{\mathrm{N}+K_{\mathrm{N}}} \cdot \mathrm{X} \\
& \frac{\mathrm{dC}}{\mathrm{dt}}= \begin{cases}-Y_{\mathrm{C} 1} \cdot \frac{\mathrm{dX}}{\mathrm{dt}}-Y_{\mathrm{C} 2} \cdot \mathrm{X} & \mathrm{N}>0 \\
-Y_{\mathrm{C} 1}^{\star} \cdot \frac{\mathrm{dX}}{\mathrm{dt}}-Y_{\mathrm{C} 2}^{\star} \cdot \mathrm{X} & \mathrm{q}>\mathrm{q}_{\min } \\
-Y_{\mathrm{C} 2}^{\star \star} \cdot \mathrm{X} & \mathrm{q} \leq \mathrm{q}_{\min }\end{cases} \\
& \frac{\mathrm{dH}_{2}}{\mathrm{dt}}= \begin{cases}Y_{\mathrm{H}_{2} 1} \cdot \frac{\mathrm{dX}}{\mathrm{dt}}+Y_{\mathrm{H}_{2} 2} \cdot \mathrm{X} & \mathrm{N}>0 \\
Y_{\mathrm{H}_{2} 1}^{\star} \cdot \frac{\mathrm{dX}}{\mathrm{dt}}+Y_{\mathrm{H}_{2} 2}^{\star} \cdot \mathrm{X} & \mathrm{q}>\mathrm{q}_{\text {min }} \\
Y_{\mathrm{H}_{2} 2}^{\star \star} \cdot \mathrm{X} & \mathrm{q} \leq \mathrm{q}_{\min }\end{cases}
\end{aligned}
$$

\subsubsection{The piecewise Contois model}

The Contois model is an improvement of the Droop model [20]. In the Contois model, the apparent half velocity constant $K_{\mathrm{S}} \cdot \mathrm{X}$ increases with the increasing biomass concentration, shown in Equation (8), which leads to a decrease of simulated bacteria growth rate in a higher biomass concentration. This is because bacteria have an optimum concentration even in the presence of sufficient nutrients [20]. Hence, the Contois model is more accurate than the Droop model when biomass concentration is high.

$$
\frac{\mathrm{dS}}{\mathrm{dt}}=-Y_{\mathrm{S}} \cdot \frac{\mathrm{S}}{\mathrm{S}+K_{\mathrm{S}} \cdot \mathrm{S}} \cdot \mathrm{X}
$$

Similar to the piecewise Droop model, the piecewise Contois model is also divided into three sub-models. Equations (9a) to (9e) show the details of piecewise Contois model. 


$$
\begin{aligned}
& \frac{\mathrm{dX}}{\mathrm{dt}}= \begin{cases}\mu_{\max } \cdot \frac{\mathrm{C}}{\mathrm{C}+K_{\mathrm{C}} \cdot \mathrm{X}} \cdot \frac{\mathrm{N}}{\mathrm{N}+K_{\mathrm{N}} \cdot \mathrm{X}} \cdot \mathrm{X} & \mathrm{N}>0 \\
\mu_{0} \cdot \frac{\mathrm{C}}{\mathrm{C}+K_{\mathrm{C}} \cdot \mathrm{X}} \cdot \mathrm{X} & \mathrm{q}>\mathrm{q}_{\min } \\
0 & \mathrm{q} \leq \mathrm{q}_{\min }\end{cases} \\
& \frac{\mathrm{dq}}{\mathrm{dt}}= \begin{cases}Y_{\mathrm{q}} \cdot \mu_{\max } \cdot \frac{\mathrm{N}}{\mathrm{N}+K_{\mathrm{N}} \cdot \mathrm{X}}-\mu_{\max } \cdot \frac{\mathrm{C}}{\mathrm{C}+K_{\mathrm{C}} \cdot \mathrm{X}} \cdot \frac{\mathrm{N}}{\mathrm{N}+K_{\mathrm{N}} \cdot \mathrm{X}} \cdot \mathrm{q} & \mathrm{N}>0 \\
-\mu_{0} \cdot \frac{\mathrm{C}}{\mathrm{C}+K_{\mathrm{C}} \cdot \mathrm{X}} \cdot \mathrm{q} & \mathrm{q}>\mathrm{q}_{\min } \\
0 & \mathrm{q} \leq \mathrm{q}_{\min }\end{cases} \\
& \frac{\mathrm{dN}}{\mathrm{dt}}=-Y_{\mathrm{N}} \cdot \mu_{\max } \cdot \frac{\mathrm{N}}{\mathrm{N}+K_{\mathrm{N}} \cdot \mathrm{X}} \cdot \mathrm{X} \\
& \frac{\mathrm{dC}}{\mathrm{dt}}= \begin{cases}-Y_{\mathrm{C} 1} \cdot \frac{\mathrm{dX}}{\mathrm{dt}}-Y_{\mathrm{C} 2} \cdot \mathrm{X} & \mathrm{N}>0 \\
-Y_{\mathrm{C} 1}^{\star} \cdot \frac{\mathrm{dX}}{\mathrm{dt}}-Y_{\mathrm{C} 2}^{\star} \cdot \mathrm{X} & \mathrm{q}>\mathrm{q}_{\min } \\
-Y_{\mathrm{C} 2}^{\star \star} \cdot \mathrm{X} & \mathrm{q} \leq \mathrm{q}_{\min }\end{cases} \\
& \frac{\mathrm{dH}_{2}}{\mathrm{dt}}= \begin{cases}Y_{\mathrm{H}_{2} 1} \cdot \frac{\mathrm{dX}}{\mathrm{dt}}+Y_{\mathrm{H}_{2} 2} \cdot \mathrm{X} & \mathrm{N}>0 \\
Y_{\mathrm{H}_{2} 1}^{\star} \cdot \frac{\mathrm{dX}}{\mathrm{dt}}+Y_{\mathrm{H}_{2} 2}^{\star} \cdot \mathrm{X} & \mathrm{q}>\mathrm{q}_{\min } \\
Y_{\mathrm{H}_{2} 2}^{\star \star} \cdot \mathrm{X} & \mathrm{q} \leq \mathrm{q}_{\min }\end{cases}
\end{aligned}
$$

\subsubsection{Switch functions}

Switch functions are used to combine different sub-models and mediate the start and termination of each sub-model. They are widely used in fermentation process simulation [35, 36]. An example of a switch function is shown in Equation (10) where by $f(x)$ equals to 1 when $x>\alpha$, otherwise $f(x)$ is 0 . The sharpness of switch functions is determined by the sharpness parameter $\gamma$. Figure 1 
shows the switch function at different values of $\gamma$.

$$
f(x)=0.5 \cdot\left(1+\frac{x-\alpha}{\sqrt{(x-\alpha)^{2}+\gamma^{2}}}\right)
$$

In the current research, two switch functions are used to combine the three different growth phases. Equation (11) is used to combine the primary growth phase with the secondary growth phase. When glutamate is presented in the culture, Equation (11) equals to 1 and therefore the growth rate of biomass is calculated by the first sub-expression in Equation (7a). When glutamate is consumed, Equation (11) equals to zero and stimulates the start of the second sub-expression in Equation (7a). Similarly, Equation (12) is used to combine the secondary growth phase with the stationary phase. As the transition between different growth phases are fast and smooth, the sharpness parameter in both switch functions is chosen as 0.1 so that the switch from one subequation to another sub-equation is rapid and errors will not be induced.

$$
\begin{gathered}
F(\mathrm{~N})=\frac{\mathrm{N}}{\left(\mathrm{N}^{2}+\gamma^{2}\right)^{0.5}} \\
F(\mathrm{q})=0.5 \cdot \frac{\left(\left(\mathrm{q}-\mathrm{q}_{\text {min }}\right)^{2}\right)^{0.5}+\left(\mathrm{q}-\mathrm{q}_{\text {min }}\right)}{\left(\left(\mathrm{q}-\mathrm{q}_{\text {min }}\right)^{2}+\gamma^{2}\right)^{0.5}}
\end{gathered}
$$

\subsection{Parameter estimation methods}

In this section the mathematical method used to obtain parameters in both piecewise models is described. With the dynamic model designed, several parameters need to be found, to ensure that the model better reflects reality. This resulted in a parameter estimation problem where the parameters that best fit experimental data needed to be determined. The parameter estimation for the dynamic model was conducted by setting up an optimisation problem. A general optimisation problem is defined as:

$\min f(x)$ 
subject to:

$$
\begin{aligned}
& h(x)=0 \\
& g(x) \leq 0
\end{aligned}
$$

where $x \in R^{n}, f(x): R^{n} \rightarrow R, h(x): R^{n} \rightarrow R^{m}$ and $g(x): R^{n} \rightarrow R^{r}, n$ is the number of variables, $m$ is the number of equality constraints and $r$ is the number of inequality constraints. The objective of an optimisation problem is to find the values of $x$, for which the minimum value of $f(x)$ is achieved such that is satisfies the constraints $h(x)$ and $g(x)$.

In order to obtain the parameters that best fit experimental data, the following optimisation problem was proposed:

$$
\min \sum_{i=1}^{n} \sum_{j=1}^{D P_{i}}\left(x_{i j}-d_{i j}\right)^{2} \frac{2}{\max _{i=1,2, \ldots, n}\left\{d_{i}\right\}+\min _{i=1,2, \ldots, n}\left\{d_{i}\right\}}
$$

subject to:

$$
h(x)=0
$$

$$
g(x) \leq 0
$$

where $n$ is the number of variables for which experimental data is relevant, $D P$ is the number of data points corresponding to variable $x_{i}, d_{i j}$ is the particular data point $j$ corresponding to variable $x_{i}$. Kinetic and mass balance equations are written in Equation (14), and bound constraints are written in Equation (15).

The optimisation problem (Equations (13) to (15)) is a least squares problem, where the difference between the experimental data points, and the dynamic model is minimised. The latter term $\frac{2}{\max _{i=1,2, \ldots, n}\left\{d_{i}\right\}+\min _{i=1,2, \ldots, n}\left\{d_{i}\right\}}$ is a weight factor appended to the objective function which is unique to 
each variable's data points.

Several methodologies exist to optimise a system of differential algebraic equations (DAE). Computational study [38] has shown that the best approach to optimise a DAE system is to fully discretise the system, transforming the system of DAE into a series of nonlinear algebraic equations and then nonlinear optimisation is used to solve the problem. This method was used to optimise the parameters for this dynamic model. Discretisation of the DAE system in the current work was carried out through an implicit Euler method; given its implicit nature this method is very robust even when faced with stiff systems (presents A-stability) [29], and thus the accuarcy of current parameter estimation process can be guaranteed. The system layout and optimisation was done through Pyomo [39], using IPOPT [40] as the optimisation library.

\section{Results and discussion}

\subsection{Parameter estimation in piecewise models}

Parameters in the piecewise Droop model and the piecewise Contois model are shown in Table 1. To verify the accuracy of parameters calculated in the current study, Figures 2 and 3 compare the experimental results with the simulation results of the two piecewise models. Both of the piecewise models fit experimental results in different growth phases very well, which indicates that the current piecewise models can be further used for PNS biohydrogen process design and optimisation.

\subsection{Effects of operating conditions on hydrogen production}

The piecewise models are constructed to analyse the influence of operating conditions on hydrogen production. These are the ratio of initial glutamate concentration to initial glycerol concentration (N/C ratio); initial biomass concentration; operating time on hydrogen production and glycerol conversion efficiency. In this section the piecewise Contois model is selected as the simulation results of both piecewise models are very similar.

\subsubsection{Effects of initial $N / C$ ratio}

Glycerol is the main carbon source for bacterial growth when glutamate is present, and is the main driver for hydrogen production along with bacteria maintenance when glutamate is depleted. Glycerol conversion efficiency and total hydrogen production are strongly dependent on initial N/C 
ratio. The effect of $\mathrm{N} / \mathrm{C}$ ratio is complicated; a high $\mathrm{N} / \mathrm{C}$ ratio can facilitate bacteria growth and improve biomass concentration. The high biomass concentration leads to higher total hydrogen production (Equation (9e)).However, electrons from glycerol consumption are used mainly for cell growth instead of hydrogen production when initial N/C ratio is high. As a result, high N/C ratio also decreases the conversion efficiency of glycerol and restricts the average hydrogen production.

In this section, the operating condition is shown in Table 2, and the range of $\mathrm{N} / \mathrm{C}$ ratio is from 0 to 1 . Figure 4 shows the influence of $\mathrm{N} / \mathrm{C}$ ratio on glycerol conversion $\left(\mathrm{mol} \mathrm{H}_{2} / \mathrm{mol}\right.$ glycerol, Figure 4(a)), hydrogen production (Figure 4(b)) and glutamate utilisation (mol $\mathrm{H}_{2} / \mathrm{mol}_{\text {glutamate, }}$ Figure 4(c)). Because glutamate does not provide electrons for hydrogen production, this utilisation parameter is used to balance the investment cost of glutamate and production of hydrogen.

Although glutamate utilisation keeps decreasing with the increasing N/C ratio (Figure 4(c)), from Figure 4(a) the optimal initial N/C ratio for hydrogen production is found to be 0.27 which is similar to the experimental result of 0.2 reported by Sabourin-Provost and Hallenbeck [41]. In their experiments, glycerol concentration was fixed at $10 \mathrm{mM}$ and glutamate concentration was tested at $0 \mathrm{mM}, 2 \mathrm{mM}, 4 \mathrm{mM}$ and $6 \mathrm{mM}$. They found that the experiment with $2 \mathrm{mM}$ glutamate gave the highest hydrogen yield. Theoretically, the maximum glycerol utilisation is $7 \mathrm{~mol} \mathrm{H}_{2} / \mathrm{mol}$ glycerol if all glycerol is used for hydrogen production (Equation (16)). The highest glycerol conversion found in the simulation at a $\mathrm{N} / \mathrm{C}$ ratio is $3.30 \mathrm{H}_{2} / \mathrm{mol}$ glycerol, $47.1 \%$ of the theoretical maximum conversion. This efficiency is similar with the general acetate conversion efficiency reported by $\mathrm{Oh}$ [8], but much lower than the previous result of $75 \%$ reported by Sabourin-Provost and Hallenbeck where glycerol was selected as the carbon source [41].

$$
\mathrm{C}_{3} \mathrm{H}_{8} \mathrm{O}_{3}+3 \mathrm{H}_{2} \mathrm{O} \rightarrow 3 \mathrm{CO}_{2}+7 \mathrm{H}_{2}
$$

The effects of N/C ratio on glycerol conversion efficiency can be considered by three case studies. In the first case ((Figure 4(d))): N/C ratio is low, resulting a low glycerol conversion. This is because low $\mathrm{N} / \mathrm{C}$ ratio leads to a short primary growth phase and bacteria are not able to grow sufficiently. As a result, there is not enough bacteria to consume glycerol. In the second case (Figure 4(f)): 
$\mathrm{N} / \mathrm{C}$ ratio is very high, glutamate concentration is excessive and causes the fermentation process to proceed in the primary growth phase where most of the electrons provided by glycerol are used for bacterial growth instead of hydrogen production. A sharp decline of hydrogen production is found, as a result. Glycerol is depleted further ensuring the low hydrogen production. Because glutamate is sufficient, the primary growth period lasts for a long time and exhausts most of glycerol. Hydrogen production is terminated due to the depletion of glycerol and the total hydrogen production is not dependent on $\mathrm{N} / \mathrm{C}$ ratio.

In the final case (Figure $4(\mathrm{e})$ ), the optimised $\mathrm{N} / \mathrm{C}$ ratio is around 0.27 , the glutamate present is sufficient to maintain bacterial growth while hydrogen production is markedly increased. The fermentation process is dominated by the primary growth phase, which is important to guarantee a high biomass concentration, as well as the secondary growth phase, which is found experimentally to have the highest hydrogen production rate. Glycerol is almost completely consumed at the end of the fermentation process, confirming both hydrogen production and glycerol conversion efficiency are much higher than before.

\subsubsection{Effects of initial biomass concentration}

The rate of hydrogen production increases with the biomass concentration in the culture. However, high biomass concentrations result in high consumption of glycerol for bacterial maintenance. As a result, the trade-off effect of initial biomass concentration on hydrogen production should be analysed.

The operating conditions in this section is shown in Table 2, and initial biomass concentration changes from $0.1 \mathrm{~g} / \mathrm{L}$ to $0.8 \mathrm{~g} / \mathrm{L}$. By simulation, the current work found that the optimal N/C ratio is almost independent (from 0.28 to 0.24 ) of initial biomass concentration. However, maximum glycerol conversion increases from $2.89 \mathrm{~mol} / \mathrm{mol}$ (41.3\% of maximum theoretical conversion) to 4.51 $\mathrm{mol} / \mathrm{mol}$ ( $64.4 \%$ of maximum theoretical conversion) when initial biomass concentration is increased from $0.1 \mathrm{~g} / \mathrm{L}$ to $0.8 \mathrm{~g} / \mathrm{L}$. The maximum glycerol conversion efficiency of $64.4 \%$ is much closer to the previous result from Sabourin-Provost and Hallenbeck Sabourin-Provost and Hallenbeck [41]. However, the highest biomass utilisation $\left(\mathrm{mmol} \mathrm{H}_{2} / \mathrm{g}\right.$ initial biomass) decreases from $578.0 \mathrm{mmol} \cdot \mathrm{g}$ biomass $^{-1}$ to $112.75 \mathrm{mmol} \cdot \mathrm{g}$ biomass ${ }^{-1}$ with increasing initial biomass concentration. 
At an optimal $\mathrm{N} / \mathrm{C}$ ratio $(0.25)$, glycerol is almost completely consumed by bacteria at the termination of fermentation and independent of the initial biomass concentration. When the initial biomass concentration is low, much more glycerol is used for bacteria growth rather than hydrogen production compared to the case when the initial biomass concentration is high. As a result, the conversion efficiency of glycerol increases with increasing initial biomass concentration. However, as more bacteria have to be cultivated for a higher initial biomass concentration, the investment cost may be increased and biomass utilisation is decreased. Therefore, an intermediate initial biomass concentration is preferred to balance the glycerol conversion efficiency and biomass utilisation.

\subsubsection{Effects of operating time}

It is also important to find the optimal operating time for the fermentation process. Hydrogen production is increased by extending operating time, the average hydrogen productivity $\left(\frac{\mathrm{H}_{2}}{\mathrm{t}}\right)$ of fermentation process may decrease due to the lower hydrogen production rate in the stationary phase compared to it in the secondary growth phase. To explore the effect of operating time on hydrogen production, the operating time is altered from 80 hours to 300 hours and the detailed operating condition is shown in Table 2.

By simulation, it is found that the highest average hydrogen productivity is $27.3 \mathrm{~mL} \cdot \mathrm{g} \mathrm{biomass}{ }^{-1} \cdot \mathrm{hr}^{-1}$, peaking at the point where the operating time is 110 hours. The fermentation process terminates in the middle of the secondary growth phase when the operating time is 110 hours, instead of the stationary phase when the operating time is 300 hours. It is because hydrogen production rate in the secondary growth phase is enhanced by both bacteria growth rate and bacteria biomass concentration (shown in Equation (9e)). With the extension of the operating time, biomass concentration increases but the bacterial growth rate decreases because of the decreasing concentration of glycerol. Therefore the hydrogen production rate is decreased due to the trade-off effect.

\subsection{Design of short term fermentation process}

To design a 30-day batch fermentation process to maximise hydrogen productivity, the initial biomass concentration in this process is chosen as $0.1 \mathrm{~g} \cdot \mathrm{L}^{-1}$, which is a close value to the one used in previous experimental work $[12,42]$. As $R$. palustris growth rate and hydrogen production rate are strongly dependent on the concentration of glycerol and glutamate, the optimal initial concen- 
trations of glycerol and glutamate in this process need to be identified. Therefore, in the current research the initial glycerol concentration changes from $10 \mathrm{mM}$ to $30 \mathrm{mM}$ and the initial glutamate concentration changes from $2 \mathrm{mM}$ to $10 \mathrm{mM}$. The optimal concentrations will be determined at the point where total hydrogen production is maximum.

The optimal operating conditions and results of this process is shown in Table 3. From the table, the initial $\mathrm{N} / \mathrm{C}$ ratio of 0.27 is seen to perform the best, similar to the ratio of 0.25 found in Section 4.2.1. It can be seen that glycerol conversion efficiency is $58 \%$, lower than the $64.4 \%$ found in Section 4.2.2. This is probably because the initial biomass concentration is not chosen well, as this value is set similar with previous research for the comparison. Both glutamate and glycerol are depleted at the end of fermentation process. The hydrogen productivity is found to be $37.7 \mathrm{~mL} \cdot \mathrm{g}$ biomass $^{-1} \cdot \mathrm{hr}^{-1}$.

If the fermentation process is terminated at the time where maximum average hydrogen productivity occurs (mentioned in Section 4.2.3), the current simulation finds that operating time should be 13 days and highest hydrogen productivity is $58.4 \mathrm{~mL} \cdot \mathrm{g}$ biomass ${ }^{-1} \cdot \mathrm{hr}^{-1}$. The operating conditions and results of this 13-day process is also shown in Table 3 . However, in this case glycerol remains at the end of fermentation process (Table 3) and glycerol conversion efficiency is only $37 \%$, which is only $63.8 \%$ of the 30 -day process and has the potential to increase the material cost. Therefore, a financial analysis is necessary in future work to decide which process is more profitable.

Compared to the previous research, the current 30-day batch process shows the same hydrogen productivity $\left(37.7 \mathrm{~mL} \cdot \mathrm{g}\right.$ biomass $\left.{ }^{-1} \cdot \mathrm{hr}^{-1}\right)$ with the one reported by Boran et al. [12] (37.9 $\mathrm{mL} \cdot \mathrm{g}$ biomass ${ }^{-1} \cdot \mathrm{hr}^{-1}, 30$ days $)$ but much higher than that reported by Lee et al. [13] $(16.7 \mathrm{~mL} \cdot \mathrm{g}$ biomass ${ }^{-1} \cdot \mathrm{hr}^{-1}, 24$ days) as well as by green algal and cyanobacterial processes [9, 10, 23]. Furthermore, as most of the previous processes are designed as fed-batch system, fresh culture has to be added either continuously or intermittently during operation. Thus additional auxiliary equipment has to be included and the possibility of contamination is increased compared to the current optimised batch process. The comparison indicates that the optimisation of operating conditions is essential for designing related scale-up processes.

In terms of the future work, light intensity which determines the reduction energy that cells 
can obtain $[6,7]$ has to be included in the current model, as previous publications found that both PNS cells growth and hydrogen production are strongly dependent on light intensity [25, 43]. For microorganisms such as PNS and green algae, a low light intensity usually limits cell growth while intense illumination leads to a photo-inhibition effect on cell growth [44, 45]. Therefore, there is a trade-off value that optimises photofermentations. In the future work, we thus intend to include the effects of light intensity in the dynamic evolution of the PNS biohydrogen production process and include its optimal determination. For example, the Aiba model (Equation (17)) can be embedded in the current models as it is able to describe both photo-limitation and photo-inhibition [46] affecting the specific growth rate of cells.

$$
\mu=\frac{I}{I+k_{s}+\frac{I^{2}}{k_{i}}}
$$

where $\mu$ is specific growth rate, $I$ is light intensity, $k_{s}$ is light saturation term and $k_{i}$ is photoinhibition term.

\section{Conclusions}

Two piecewise models were constructed to simulate the biohydrogen production process of $R$. palustris using glycerol as the carbon source. Parameters were calculated via discretisation optimisation. An optimal glutamate to glycerol ratio found by simulation was 0.25 by the current model. It was concluded that the optimal glutamate to glycerol ratio is independent of initial biomass concentration. The maximum glycerol conversion efficiency is strongly affected by initial biomass concentration, and computationally peaks at $64.4 \%$. An optimised batch process lasting for 30 days was proposed in the present study, with a hydrogen productivity of $37.7 \mathrm{~mL} \cdot \mathrm{g}$ biomass ${ }^{-1} \cdot \mathrm{hr}^{-1}$.

\section{Acknowledgment}

The author D. Zhang gratefully acknowledges the support from his family, authors N. Xiao and Dr. K. T. Mahbubani are funded through the KACST-Cambridge Center for Advanced Material Manufacture, the author E. A. del Rio-Chanona is found by CONACyT scholarship No. 522530 from the Secretariat of Public Education and the Mexican government. The authors wish to thank Mr. Fabio Fiorelli for his invaluable advice and support during the preparation of this work. 
Table 1: Parameters in the piecewise Droop model.

The piecewise Droop model

\begin{tabular}{|c|c|c|c|c|c|}
\hline Parameter & Value & Unit & Parameter & Value & Unit \\
\hline$\mu_{\max }$ & 0.012 & $\mathrm{hr}^{-1}$ & $Y_{\mathrm{C} 1}$ & 23.63 & $\mathrm{mmol} \cdot \mathrm{g}^{-1}$ \\
\hline$\mu_{0}$ & 0.012 & $\mathrm{hr}^{-1}$ & $Y_{\mathrm{C} 1}^{\star}$ & 56.94 & $\mathrm{mmol} \cdot \mathrm{g}^{-1}$ \\
\hline$K_{\mathrm{C}}$ & 3.694 & $\mathrm{mM}$ & $Y_{\mathrm{C} 2}$ & 0.0 & $\mathrm{mmol} \cdot \mathrm{g}^{-1} \cdot \mathrm{hr}^{-1}$ \\
\hline$K_{\mathrm{C}}^{\star}$ & 17.94 & $\mathrm{mM}$ & $Y_{\mathrm{C} 2}^{\star}$ & 0.0 & $\mathrm{mmol} \cdot \mathrm{g}^{-1} \cdot \mathrm{hr}^{-1}$ \\
\hline $\mathrm{q}_{\min }$ & 0.830 & - & $Y_{\mathrm{C} 2}^{\star \star}$ & 0.078 & $\mathrm{mmol} \cdot \mathrm{g}^{-1} \cdot \mathrm{hr}^{-1}$ \\
\hline$Y_{\mathrm{N}}$ & 76.58 & $\mathrm{mmol} \cdot \mathrm{g}^{-1}$ & $Y_{\mathrm{H}_{2} 1}^{\star}$ & 3658 & $\mathrm{~mL} \cdot \mathrm{g}^{-1}$ \\
\hline$K_{\mathrm{N}}$ & 0.507 & $\mathrm{mM}$ & $Y_{\mathrm{H}_{2} 2}^{\star}$ & 1.720 & $\mathrm{~mL} \cdot \mathrm{g}^{-1} \cdot \mathrm{hr}^{-1}$ \\
\hline$Y_{\mathrm{q}}$ & 10.43 & - & $Y_{\mathrm{H}_{2} 2}^{\star \star}$ & 4.900 & $\mathrm{~mL} \cdot \mathrm{g}^{-1} \cdot \mathrm{hr}^{-1}$ \\
\hline$Y_{\mathrm{H}_{2} 1}$ & 1547 & $\mathrm{~mL} \cdot \mathrm{g}^{-1}$ & & & \\
\hline \multicolumn{6}{|c|}{ The piecewise Contois model } \\
\hline Parameter & Value & Unit & Parameter & Value & Unit \\
\hline$\mu_{\max }$ & 0.010 & $\mathrm{hr}^{-1}$ & $Y_{\mathrm{C} 1}$ & 23.70 & $\mathrm{mmol} \cdot \mathrm{g}^{-1}$ \\
\hline$\mu_{0}$ & 0.008 & $\mathrm{hr}^{-1}$ & $Y_{\mathrm{C} 1}^{\star}$ & 56.48 & $\mathrm{mmol} \cdot \mathrm{g}^{-1}$ \\
\hline$K_{\mathrm{C}}$ & 5.425 & $\mathrm{mM}$ & $Y_{\mathrm{C} 2}$ & 0.0 & $\mathrm{mmol} \cdot \mathrm{g}^{-1} \cdot \mathrm{hr}^{-1}$ \\
\hline$K_{\mathrm{C}}^{\star}$ & 33.75 & $\mathrm{mM}$ & $Y_{\mathrm{C} 2}^{\star}$ & 0.0 & $\mathrm{mmol} \cdot \mathrm{g}^{-1} \cdot \mathrm{hr}^{-1}$ \\
\hline$q_{\min }$ & 0.840 & - & $Y_{\mathrm{C} 2}^{\star \star}$ & 0.078 & $\mathrm{mmol} \cdot \mathrm{g}^{-1} \cdot \mathrm{hr}^{-1}$ \\
\hline$Y_{\mathrm{N}}$ & 76.58 & $\mathrm{mmol} \cdot \mathrm{g}^{-1}$ & $Y_{\mathrm{H}_{2} 1}^{\star}$ & 3021 & $\mathrm{~mL} \cdot \mathrm{g}^{-1}$ \\
\hline$K_{\mathrm{N}}$ & 0.507 & $\mathrm{mM}$ & $Y_{\mathrm{H}_{2} 2}^{\star}$ & 2.535 & $\mathrm{~mL} \cdot \mathrm{g}^{-1} \cdot \mathrm{hr}^{-1}$ \\
\hline$Y_{\mathrm{q}}$ & 10.43 & - & $Y_{\mathrm{H}_{2} 2}^{\star \star}$ & 4.900 & $\mathrm{~mL} \cdot \mathrm{g}^{-1} \cdot \mathrm{hr}^{-1}$ \\
\hline$Y_{\mathrm{H}_{2} 1}$ & 1553 & $\mathrm{~mL} \cdot \mathrm{g}^{-1}$ & & & \\
\hline
\end{tabular}


Table 2: Operating conditions in Section 4.2

\begin{tabular}{|l|l|l|l|}
\hline & Section 4.2 .1 & Section 4.2 .2 & Section 4.2 .3 \\
\hline Initial biomass concentration & $0.20 \mathrm{~g} \cdot \mathrm{L}^{-1}$ & {$\left[0.1 \mathrm{~g} \cdot \mathrm{L}^{-1}, 0.8 \mathrm{~g} \cdot \mathrm{L}^{-1}\right]$} & $0.20 \mathrm{~g} \cdot \mathrm{L}^{-1}$ \\
Initial glutamate concentration & {$[0 \mathrm{mM}, 20 \mathrm{mM}]$} & {$[0 \mathrm{mM}, 20 \mathrm{mM}]$} & $1.8 \mathrm{mM}$ \\
Initial glycerol concentration & $20 \mathrm{mM}$ & $20 \mathrm{mM}$ & $20 \mathrm{mM}$ \\
operating time & $300 \mathrm{hr}$ & $300 \mathrm{hr}$ & {$[80 \mathrm{hr}, 300 \mathrm{hr}]$} \\
Medium volume & $200 \mathrm{~mL}$ & $200 \mathrm{~mL}$ & $200 \mathrm{~mL}$ \\
\hline
\end{tabular}


Table 3: Simulation of short-term photofermentation processes

\begin{tabular}{|l|l|l|}
\hline Optimal operating conditions & 30 -day process & 13 -day process \\
\hline Initial biomass concentration & $0.10 \mathrm{~g} \cdot \mathrm{L}^{-1}$ & $0.1 \mathrm{~g} \cdot \mathrm{L}^{-1}$ \\
Initial glutamate concentration & $8.1 \mathrm{mM}$ & $8.1 \mathrm{mM}$ \\
Initial glycerol concentration & $30 \mathrm{mM}$ & $30 \mathrm{mM}$ \\
operating time & 30 days & 13 days \\
Medium volume & $200 \mathrm{~mL}$ & $200 \mathrm{~mL}$ \\
\hline Simulation Results & 30 -day process & $13-$ day process \\
\hline Total hydrogen production & $542.4 \mathrm{~mL}$ & $350.5 \mathrm{~mL}$ \\
Final biomass concentration & $1.26 \mathrm{~g} / \mathrm{L}$ & $1.21 \mathrm{~g} / \mathrm{L}$ \\
Optimal N/C ratio & 0.27 & 0.27 \\
Glycerol conversion efficiency & 0.58 & 0.37 \\
Hydrogen productivity & $37.7 \mathrm{~mL} \cdot \mathrm{g}$ biomass \\
Final glutamate concentration & $0.0 \mathrm{mM}$ & $58.4 \mathrm{~mL} \cdot \mathrm{g}$ biomass \\
Final glycerol concentration & $0.0 \mathrm{mM}$ & $0.0 \mathrm{mM}$ \\
\hline
\end{tabular}




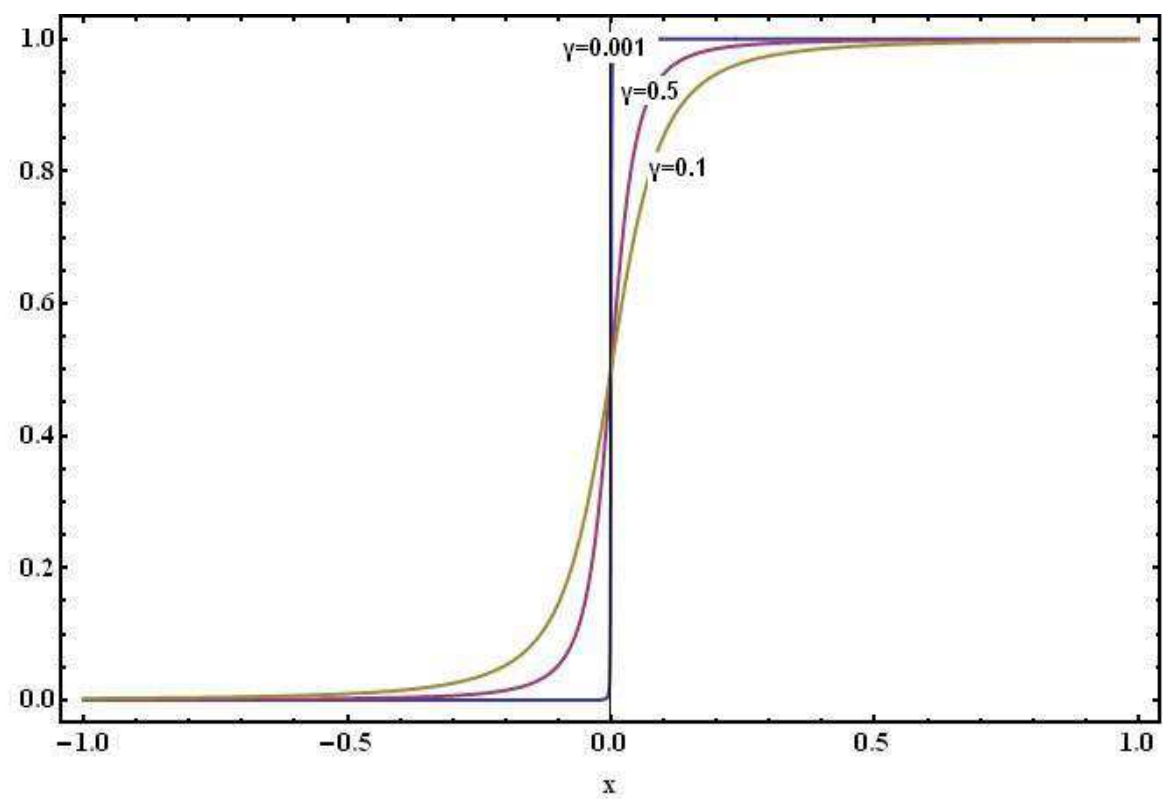

Figure 1: Example of switch function. 

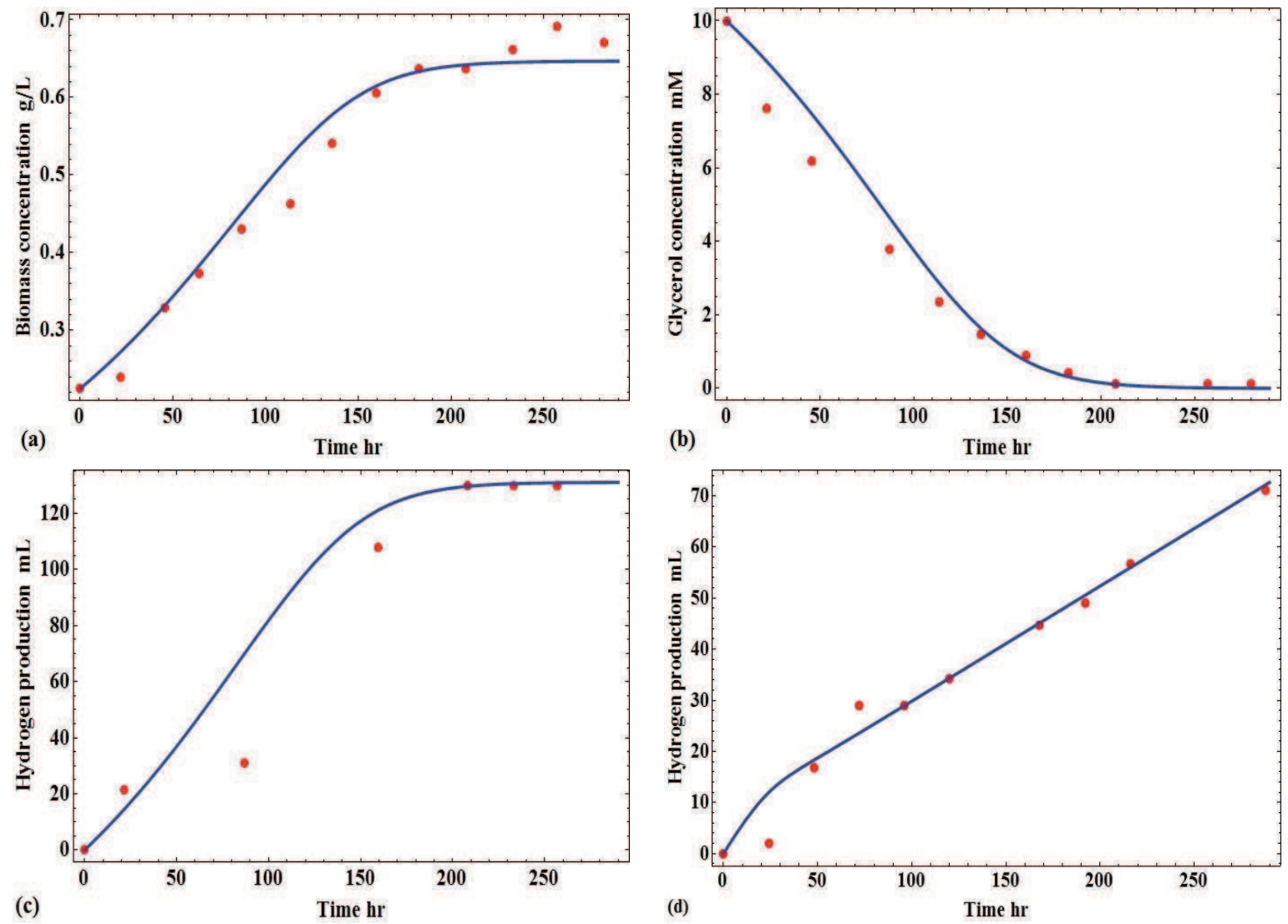

Figure 2: Comparison of experimental results and simulation results of piecewise Contois model. (a), biomass concentration during the time course of primary growth period; (b), glycerol concentration during the time course of primary growth period; (c), hydrogen production during the time course of primary growth period; Solid line: simulation results. Circle points: experimental results. 

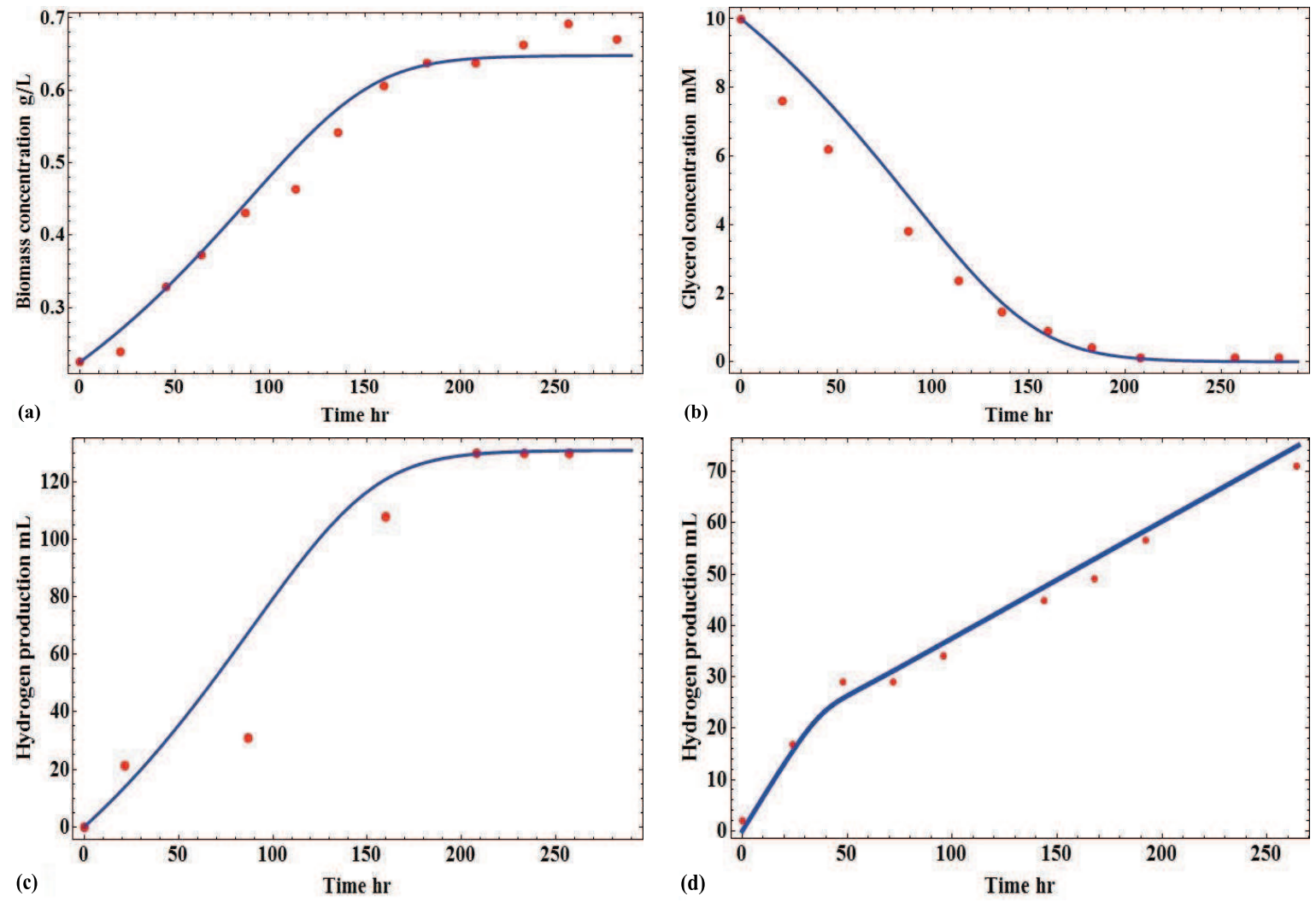

Figure 3: Comparison of experimental results and simulation results of piecewise Droop model. (a), biomass concentration during the time course of primary growth period; (b), glycerol concentration during the time course of primary growth period; (c), hydrogen production during the time course of primary growth period; (d), hydrogen production during the time course of secondary growth period and stationary period. Solid line: simulation results. Circle points: experimental results. 

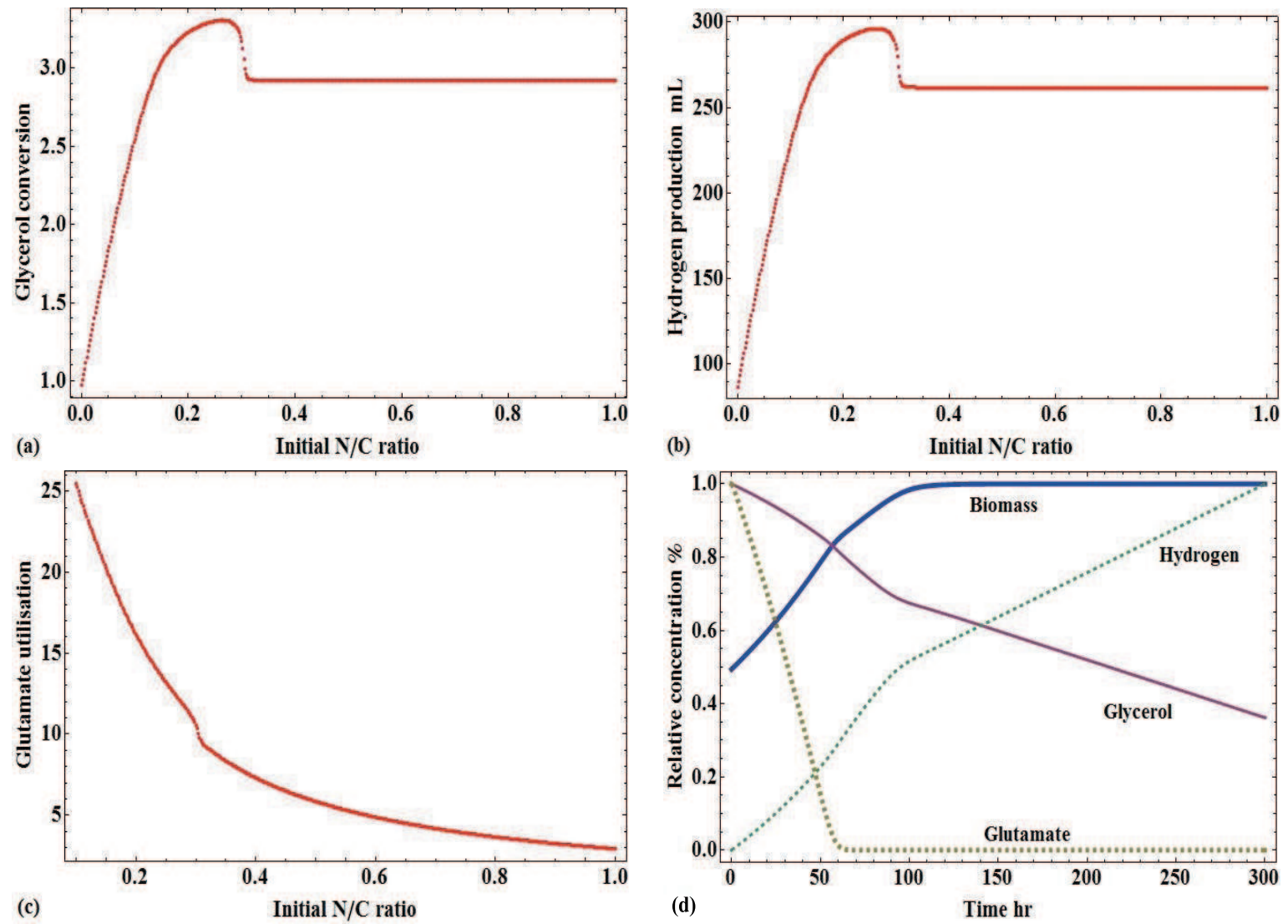

(b)
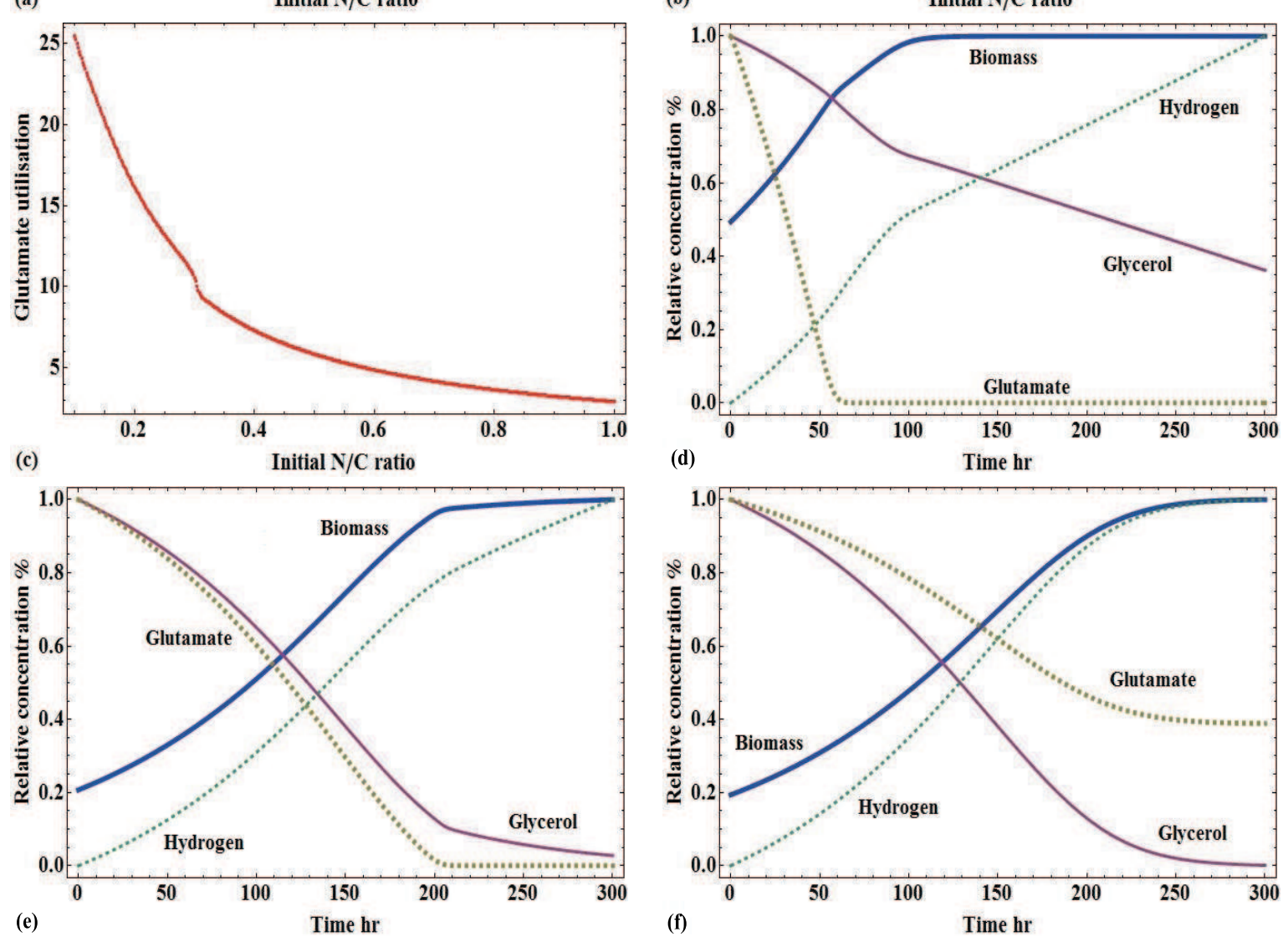

Figure 4: Simulation results of effects of initial N/C ratio on hydrogen production. (a), Glycerol conversion w.r.t. initial N/C ratio. (b), hydrogen production and glutamate utilisation w.r.t. initial N/C ratio. (c), glutamate utilisation w.r.t. initial N/C ratio; (d) (f), concentration of biomass, nitrogen quota, glycerol and glutamate during the time course of fermentation process. The relative concentration is defined as $x(\mathrm{t}) / x_{\max }$, where $x(\mathrm{t})$ refers to the concentration of any substrates or biomass: (d), N/C ratio is 0.05 . (e), N/C ratio is 0.27 . (f), N/C ratio is 0.50. Thick solid line: biomass concentration. Thin solid line: glycerol concentration. Thick dashed line: glutamate concentration. Thin dashed line: hydrogen production. 


\section{References}

[1] P. Cooke, J. Porter, H. Pinto, A. R. Cruz, F. Zhang, Notes from the Iberian Algae Belt, European Planning Studies 19 (1) (2011) 159-173, ISSN 0965-4313, doi:10.1080/09654313.2011.525391, URL http://www.tandfonline.com/doi/abs/10.1080/09654313.2011.525391.

[2] C. Sambusiti, M. Bellucci, A. Zabaniotou, L. Beneduce, F. Monlau, Algae as promising feedstocks for fermentative biohydrogen production according to a biorefinery approach: A comprehensive review, Renewable and Sustainable Energy Reviews 44 (2015) 20-36, ISSN 13640321, doi:10.1016/j.rser.2014.12.013, URL http://linkinghub.elsevier.com/retrieve/pii/S136403211401065X.

[3] T. M. Mata, A. a. Martins, N. S. Caetano, Microalgae for biodiesel production and other applications: A review, Renewable and Sustainable Energy Reviews 14 (1) (2010) 217-232, ISSN 13640321, doi:10.1016/j.rser.2009.07.020, URL http://linkinghub.elsevier.com/retrieve/pii/S1364032109001646.

[4] R. Chaubey, S. Sahu, O. O. James, S. Maity, A review on development of industrial processes and emerging techniques for production of hydrogen from renewable and sustainable sources, Renewable and Sustainable Energy Reviews 23 (0) (2013) 443-462, ISSN 13640321, doi:10.1016/j.rser.2013.02.019, URL http://linkinghub.elsevier.com/retrieve/pii/S1364032113001214.

[5] N. Basak, D. Das, The Prospect of Purple Non-Sulfur (PNS) Photosynthetic Bacteria for Hydrogen Production: The Present State of the Art, World Journal of Microbiology and Biotechnology 23 (1) (2006) 31-42, ISSN 0959-3993, doi:10.1007/s11274-006-9190-9, URL http://link.springer.com/10.1007/s11274-006-9190-9.

[6] R. Y. Igarashi, Nitrogen Fixation: The Mechanism of the Mo-Dependent Nitrogenase, Critical Reviews in Biochemistry and Molecular Biology 38 (4) 
http://www . crbmb.com/cgi/doi/10.1080/10409230390242380.

[7] O. Kruse, J. Rupprecht, J. H. Mussgnug, G. C. Dismukes, B. Hankamer, Photosynthesis: a blueprint for solar energy capture and biohydrogen production technologies., Photochemical \& photobiological sciences : Official journal of the European Photochemistry Association and the European Society for Photobiology 4 (12) (2005) 957-70, ISSN 1474-905X, doi: 10.1039/b506923h, URL http://www.ncbi.nlm.nih.gov/pubmed/16307108.

[8] Y. Oh, Photoproduction of hydrogen from acetate by a chemoheterotrophic bacterium Rhodopseudomonas palustris P4, International Journal of Hydrogen Energy 29 (11) (2004) 1115-1121, ISSN 03603199, doi:10.1016/j.jhhydene.2003.11.008, URL http://linkinghub.elsevier.com/retrieve/pii/S0360319903003306.

[9] K. Vijayaraghavan, R. Karthik, S. Kamala Nalini, Hydrogen production by Chlamydomonas reinhardtii under light driven sulfur deprived condition, International Journal of Hydrogen Energy 34 (19) (2009) 7964-7970, ISSN 03603199, doi:10.1016/j.ijhydene.2009.08.010, URL http://linkinghub.elsevier.com/retrieve/pii/S0360319909012567.

[10] J. P. Kim, K.-R. Kim, S. P. Choi, S. J. Han, M. S. Kim, S. J. Sim, Repeated production of hydrogen by sulfate re-addition in sulfur deprived culture of Chlamydomonas reinhardtii, International Journal of Hydrogen Energy 35 (24) (2010) 13387-13391, ISSN 03603199, doi:10.1016/j.ijhydene.2009.11.113, URL http://linkinghub.elsevier.com/retrieve/pii/S0360319909019466.

[11] P. Dechatiwongse, G. C. Maitland, K. Hellgardt, Enhancement in bio-hydrogen and biomass productivity of unicellular cyanobacteirum Cyanothece using a two-stage chemostat photobioreactor system, Algal Research (provisional) .

[12] E. Boran, E. Özgür, J. van der Burg, M. Yücel, U. Gündüz, I. Eroglu, Biological hydrogen production by Rhodobacter capsulatus in solar tubular photo bioreactor, Journal of 
Cleaner Production 18 (2010) S29-S35, ISSN 09596526, doi:10.1016/j.jclepro.2010.03.018, URL http://linkinghub.elsevier.com/retrieve/pii/S0959652610001265.

[13] C.-M. Lee, G.-J. Hung, C.-F. Yang, Hydrogen production by Rhodopseudomonas palustris WP 3-5 in a serial photobioreactor fed with hydrogen fermentation effluent., Bioresource technology 102 (18) (2011) 8350-6, ISSN 1873-2976, doi:10.1016/j.biortech.2011.04.072, URL http://www.ncbi.nlm.nih.gov/pubmed/21600763.

[14] M. G. Moghaddam, Comparison of Response Surface Methodology and Artificial Neural Network in Predicting the Microwave-Assisted Extraction Procedure to Determine Zinc in Fish Muscles, Food and Nutrition Sciences 02 (08) (2011) 803-808, ISSN 2157-944X, doi:10.4236/fns.2011.28110, URL http: //www. scirp.org/journal/PaperDownload . aspx?DOI=10 .4236/fns . 2011 . 28110.

[15] M. A. Bezerra, R. E. Santelli, E. P. Oliveira, L. S. Villar, L. A. Escaleira, Response surface methodology (RSM) as a tool for optimization in analytical chemistry., Talanta 76 (5) (2008) 965-77, ISSN 1873-3573, doi:10.1016/j.talanta.2008.05.019, URL http://www.ncbi.nlm.nih.gov/pubmed/18761143.

[16] G. E. P. Box, K. B. Wilson, On the Experimental Attainment of Optimum Conditions, Journal of the Royal Statistical Society 13 (1) (1951) 1-45.

[17] R. . Mead, D. . J. . Pike, A review of response surface methodology from a biometric viewpoint., Biometrics 31 (4) (1975) 803-851.

[18] A. Gadhe, S. S. Sonawane, M. N. Varma, Evaluation of ultrasonication as a treatment strategy for enhancement of biohydrogen production from complex distillery wastewater and process optimization, International Journal of Hydrogen Energy 39 (19) (2014) 10041-10050, ISSN 03603199, doi:10.1016/j.ijhydene.2014.04.153, URL http://linkinghub.elsevier.com/retrieve/pii/S0360319914012117.

[19] D. D. Androga, P. Sevinç, H. Koku, M. Yücel, U. Gündüz, I. Eroglu, Optimization of temperature and light intensity for improved photofermentative hydrogen produc- 
tion using Rhodobacter capsulatus DSM 1710, International Journal of Hydrogen Energy 39 (6) (2014) 2472-2480, ISSN 03603199, doi:10.1016/j.ijhydene.2013.11.114, URL http://linkinghub.elsevier.com/retrieve/pii/S0360319913028772.

[20] I. Vatcheva, H. de Jong, O. Bernard, N. J. I. Mars, Experiment selection for the discrimination of semi-quantitative models of dynamical systems, Artificial Intelligence 170 (4-5) (2006) 472-506, ISSN 00043702, doi:10.1016/j.artint.2005.11.001, URL http://linkinghub.elsevier.com/retrieve/pii/S0004370205002092.

[21] K. Nath, Kinetics of two-stage fermentation process for the production of hydrogen, International Journal of Hydrogen Energy 33 (4) (2008) 1195-1203, ISSN 03603199, doi:10.1016/j.ijhydene.2007.12.011, URL http://linkinghub.elsevier.com/retrieve/pii/S0360319907007392.

[22] G. Xie, B. Liu, D. Xing, J. Ding, J. Nan, H. Ren, W. Guo, N. Ren, The kinetic characterization of photofermentative bacterium Rhodopseudomonas faecalis RLD-53 and its application for enhancing continuous hydrogen production, International Journal of Hydrogen Energy 37 (18) (2012) 13718-13724, ISSN 03603199, doi:10.1016/j.jjhydene.2012.02.168.

[23] P. Dechatiwongse, S. Srisamai, G. Maitland, K. Hellgardt, Effects of light and temperature on the photoautotrophic growth and photoinhibition of nitrogen-fixing cyanobacterium Cyanothece sp. ATCC 51142, Algal Research 5 (0) (2014) 103-111, ISSN 22119264, doi:10.1016/j.algal.2014.06.004, URL http://linkinghub.elsevier.com/retrieve/pii/S2211926414000563.

[24] Y.-Z. Wang, Q. Liao, X. Zhu, J. Li, D.-J. Lee, Effect of culture conditions on the kinetics of hydrogen production by photosynthetic bacteria in batch culture, International Journal of Hydrogen Energy 36 (21) (2011) 14004-14013, ISSN 03603199, doi:10.1016/j.ijhydene.2011.04.005, URL http://linkinghub.elsevier.com/retrieve/pii/S0360319911008366.

[25] J. Obeid, J. Magnin, J. Flaus, O. Adrot, J. Willison, R. Zlatev, Modelling of hydrogen production in batch cultures of the photosynthetic bac- 
terium Rhodobacter capsulatus, International Journal of Hydrogen Energy 34 (1) (2009) 180-185, ISSN 03603199, doi:10.1016/j.ijhydene.2008.09.081, URL http://linkinghub.elsevier.com/retrieve/pii/S0360319908011920.

[26] S. Alagesan, S. Gaudana, S. Krishnakumar, P. Wangikar, Model based optimization of high cell density cultivation of nitrogen-fixing cyanobacteria., Bioresource technology 148 (0) (2013) 228-33, ISSN 1873-2976, doi:10.1016/j.biortech.2013.08.144, URL http://www.ncbi.nlm.nih.gov/pubmed/24047683.

[27] J. Obeid, J.-M. Flaus, O. Adrot, J.-P. Magnin, J. C. Willison, State estimation of a batch hydrogen production process using the photosynthetic bacteria Rhodobacter capsulatus, International Journal of Hydrogen Energy 35 (19) (2010) 10719-10724, ISSN 03603199, doi:10.1016/j.jjhydene.2010.02.051, URL http://linkinghub.elsevier.com/retrieve/pii/S0360319910003332.

[28] N. Basak, A. K. Jana, D. Das, D. Saikia, Photofermentative molecular biohydrogen production by purple nonsulfur (PNS) bacteria in various modes: The present progress and future perspective, International Journal of Hydrogen Energy 39 (13) (2014) 6853-6871, ISSN 03603199, doi:10.1016/j.ijhydene.2014.02.093, URL http://linkinghub.elsevier.com/retrieve/pii/S0360319914004911.

[29] E. Hairer, G. Wanner, Solving ordinary differential equations: stiff and differential-algebraic problems II., Springer, 2nd edn., 1996.

[30] L. Brugnano, F. Mazzia, D. Trigiante, T. E. Simos, G. Psihoyios, C. Tsitouras, The Role of the Precise Definition of Stiffness in Designing Codes for the Solution of ODEs., in: AIP Conference Proceedings, AIP, 731-734, doi:10.1063/1.3241570, URL http://scitation.aip.org/content/aip/proceeding/aipcp/10.1063/1.3241570, 2009.

[31] J. L. Gosse, B. J. Engel, F. E. Rey, C. S. Harwood, L. E. Scriven, M. C. Flickinger, Hydrogen production by photoreactive nanoporous latex coatings of nongrowing Rhodopseudomonas palustris CGA009., Biotechnology Progress 23 (1) (2007) 124-30. 
[32] P. Carlozzi, A. Sacchi, Biomass production and studies on Rhodopseudomonas palustris grown in an outdoor, temperature controlled, underwater tubular photobioreactor., Journal of biotechnology 88 (3) (2001) 239-49, ISSN 0168-1656, URL http://www.ncbi.nlm.nih.gov/pubmed/11434969.

[33] P. Bondioli, L. Della Bella, An alternative spectrophotometric method for the determination of free glycerol in biodiesel, European Journal of Lipid Science and Technology 107 (3) (2005) 153-157, ISSN 1438-7697, doi:10.1002/ejlt.200401054, URL http://doi.wiley.com/10.1002/ejlt.200401054.

[34] N. S. Wang, Amino Acid Assay by Ninhydrin Colorimetric Method., Tech. Rep., Department of Chemical \& Biomolecular Engineering, University of Maryland, 2014.

[35] J. Thierie, Modeling threshold phenomena, metabolic pathways switches and signals in chemostat-cultivated cells: the Crabtree effect in Saccharomyces cerevisiae., Journal of theoretical biology 226 (4) (2004) 483-501, ISSN 0022-5193, doi:10.1016/j.jtbi.2003.10.017.

[36] P. Buchwald, FEM-based oxygen consumption and cell viability models for avascular pancreatic islets., Theoretical biology \& medical modelling 6 (5) (2009) 1-13, ISSN 1742-4682, doi:10.1186/1742-4682-6-5.

[37] S. Fouchard, J. Pruvost, B. Degrenne, M. Titica, J. Legrand, Kinetic modeling of light limitation and sulfur deprivation effects in the induction of hydrogen production with Chlamydomonas reinhardtii: Part I. Model development and parameter identification., Biotechnology and bioengineering 102 (1) (2009) 232-277, ISSN 1097-0290, doi:10.1002/bit.22034, URL http://www.ncbi.nlm.nih.gov/pubmed/18688816.

[38] L. T. Biegler, An overview of simultaneous strategies for dynamic optimization, Chemical Engineering and Processing: Process Intensification 46 (11) (2007) 1043-1053, ISSN 02552701, doi:10.1016/j.cep.2006.06.021, URL http://linkinghub.elsevier.com/retrieve/pii/S0255270107001122. 
[39] W. E. Hart, C. Laird, J.-P. Waston, D. L. Woodruff, Pyomo-Optimization Modeling in Python, Springer, 2012.

[40] A. Wächter, L. T. Biegler, On the implementation of an interior-point filter line-search algorithm for large-scale nonlinear programming, vol. 106, ISBN 1010700405, doi:10.1007/s10107004-0559-y, URL http://link.springer.com/10.1007/s10107-004-0559-y, 2005.

[41] G. Sabourin-Provost, P. C. Hallenbeck, High yield conversion of a crude glycerol fraction from biodiesel production to hydrogen by photofermentation., Bioresource technology 100 (14) (2009) 3513-7, ISSN 1873-2976, doi:10.1016/j.biortech.2009.03.027, URL http://www.ncbi.nlm.nih.gov/pubmed/19339176.

[42] A. Adessi, G. Torzillo, E. Baccetti, R. De Philippis, Sustained outdoor H2 production with Rhodopseudomonas palustris cultures in a 50L tubular photobioreactor, International Journal of Hydrogen Energy 37 (10) (2012) 8840-8849, ISSN 03603199, doi:10.1016/j.ijhydene.2012.01.081, URL http://linkinghub.elsevier. com/retrieve/pii/S0360319912001772.

[43] M. J. Barbosa, J. M. S. Rocha, J. Tramper, H. Wijffels, Acetate as a carbon source for hydrogen production by photosynthetic bacteria., Journal of biotechnology 85 (0) (2001) 25-33.

[44] I. Vass, Photoinhibition of carotenoidless reaction centers from Rhodobacter sphaeroides by visible light. Effects on protein structure and electron transport., Photosynthesis research $70(0)$ (2001) 175-184.

[45] R. J. Ritchie, The use of usolar radiation by the photosynthetic bacterium, rhodopseudomonas palustri : model simulation of conditions found in a shallow pond or a flated reactor, Photochemistry and Photobiology 89 (27) (2013) 1143-1162, doi:10.1111/php.12124.

[46] S. Aiba, Growth Kinetics of Photosynthetic Microorganisms., Advances in Biochemical Engineering 23 (0) (1982) 85-156. 